\title{
O Programa Conservador das Águas e sua Relação com o Uso da Terra em Extrema-MG
}

\author{
The Conservative of Waters Program and its Relation with Land-use in Extrema-MG
}

\author{
Guilherme Augusto Verola Mataveli', João Vitor Roque Guerrero², Michel Eustáquio Dantas Chaves ${ }^{3}$, Rodrigo \\ Cesário Justino ${ }^{4}$, Fernando Shinji Kawakubo ${ }^{5}$, Rúbia Gomes Morato ${ }^{6}$ \\ 1 Universidade de São Paulo, mataveli@usp.br \\ 2 Universidade Federal de São Carlos, jvguerrero2@gmail.com \\ 3 Universidade Federal de Lavras, micheldchaves@gmail.com \\ 4 Universidade Federal de Alfenas, rodrigofriend81@gmail.com \\ 5 Universidade de São Paulo, fskgeo@usp.br \\ 6Universidade de São Paulo, rubiagm@gmail.com \\ Recebido (Received): 06/11/2017 \\ Aceito (Accepted): 02/03/2018
}

\begin{abstract}
Resumo: O objetivo deste trabalho foi realizar uma análise multitemporal do uso da terra do município de Extrema (MG), através do Sensoriamento Remoto (SR) e da técnica Geospatial Object Based Image Analysis (GEOBIA), considerando o início dos programas de conservação ambiental de adesão voluntária presentes no município e o período atual, com foco nas Áreas de Preservação Permanente (APPs). Foram utilizadas imagens orbitais dos sensores Thematic Mapper (TM) do Landsat-5 e Operational Land Imager (OLI) do Landsat-8, além do modelo digital de elevação Shuttle Radar Topography Mission (SRTM). A classificação do uso da terra foi realizada a partir da GEOBIA em ambiente eCognition Developer ${ }^{\circledR} 64$ (ED64), que além da informação espectral também inclui outras informações importantes no processo de decisão, tais como textura e forma. Como resultado, foi identificado que entre 2006 e 2016 as áreas de mata do município aumentaram de $86 \mathrm{~km}^{2}$ para $108 \mathrm{~km}^{2}$. Além disso, foi constatado que 31\% da área do município $\left(76,5 \mathrm{~km}^{2}\right)$ são áreas de APP de acordo com a legislação vigente, e que o aumento significativo de $10 \%$ da mata em áreas de APP demonstra um comprometimento do município com a qualidade ambiental local e a efetividade do programa de conservação.
\end{abstract}

Palavras-chave: GEOBIA, APP, Conservação de Água, Extrema.

\begin{abstract}
The objective of this work was to perform a multitemporal analysis of the land-use in the city of Extrema (MG) using Remote Sensing (SR) and the Geospatial Object Based Image Analysis (GEOBIA) approach, considering the beginning of the environmental conservation programs of voluntary accession present in the municipality and the current period, focusing on the Permanent Preservation Areas (PPAs) of Extrema. Satellite images obtained from the Thematic Mapper (TM) sensor onboard Landsat-5 and the Operational Land Imager (OLI) instrument onboard Landsat-8 were used, as well as the digital elevation model derived from the Shuttle Radar Topography Mission (SRTM). GEOBIA, which uses in addition to pure spectral information other relevant information in the decision process, such as texture and shape, was performed in eCognition Developer ${ }^{\mathbb{B}} 64$ (ED64) environment in order to define the land-use in the study area. As a result, between 2006 and 2016 there was an increase of forest in the study area, increasing from 86 $\mathrm{km}^{2}$ to $108 \mathrm{~km}^{2}$. In addition, it was possible to identify that $31 \%$ of the study area $\left(76.5 \mathrm{~km}^{2}\right)$ are PPA according to the current legislation and that a significant increase of $10 \%$ of forest areas in PPA areas occurred, showing the commitment of the municipality with local environmental quality and the effectiveness of the preservation program.
\end{abstract}

Keywords: GEOBIA, PPA, Water Conservation, Extrema. 


\section{Introdução}

No início da década de 1990, a "Cúpula da Terra", também conhecida como "Eco-92", ocorrida na cidade do Rio de Janeiro, representou o primeiro passo de um longo processo de entendimento entre as nações sobre medidas concretas visando conciliar as atividades econômicas com a necessidade de proteger o planeta e assegurar qualidade de vida às próximas gerações (JACOBI, 1999), naquilo que convencionou-se chamar de desenvolvimento sustentável. Esta preocupação aumentou o rigor das leis ambientais mundo afora, principalmente em países do terceiro mundo como o Brasil, onde ainda existem vastas áreas naturais preservadas. Porém, mesmo que a legislação ambiental seja um poderoso instrumento colocado à disposição da sociedade (SEMACE, 1994) e que o Brasil apresente uma legislação ambiental rigorosa, a vastidão de seu território cria dificuldades, como a falta de informações, e, por consequência, a fiscalização do seu cumprimento (NASCIMENTO et al., 2005).

Logo, para que o desenvolvimento seja efetivamente sustentável, a tomada de decisões deve ultrapassar o campo jurídico e somar-se às demandas práticas de cada circunstância e cenário ambiental. Em face disso, torna-se necessária a adesão a um planejamento específico mais local do que nacional de ações sobre o espaço (PESSOA; FERNANDES, 2010), objetivando aplicar medidas contextuais e conceitualmente embasadas, que considerem a pluralidade de visões e, acima de tudo, as especificidades locais, com o intuito de otimizar o regido nas leis para contextos específicos.

Considerando essa crescente preocupação ambiental global e as premissas de instituir um planejamento local, o município de Extrema (MG), no qual estão localizadas algumas das principais fontes de abastecimento de água do Sistema Cantareira, um dos mais importantes reservatórios do país, e que abastece em condições normais 9 milhões de habitantes da Região Metropolitana de São Paulo (RMSP) (SABESP, 2017), adotou e colocou em prática, na primeira década do presente século, dois programas visando à manutenção e proteção dos diversos serviços ecossistêmicos prestados pelos recursos hídricos, como, por exemplo, a disponibilidade de água potável. O primeiro foi elaborado em 2005 e é um projeto municipal, intitulado "Conservador das Águas"; já em 2010, visando ampliar essa proteção, o município passou também a participar do programa "Produtor de Água", criado pela Agência Nacional de Águas (ANA).

No escopo da fiscalização e da aplicação da legislação ambiental, as geotecnologias e o sensoriamento remoto constituem-se em ferramentas imprescindíveis de auxílio nas tomadas de decisão. O sensoriamento remoto pode ser entendido como um conjunto de atividades que permite a obtenção de informações dos objetos que compõem a superfície terrestre sem a necessidade de contato direto com os mesmos (MORAES, 2002), sendo que as imagens obtidas por sensores orbitais proporcionam uma visão de conjunto multitemporal de extensas áreas da superfície terrestre, possibilitando estudos regionais e integrados (FLORENZANO, 2005).

Dentre as possíveis aplicações das técnicas de sensoriamento remoto para fiscalizar a legislação ambiental, destaca-se o monitoramento da situação das Áreas de Preservação Permanente (APPs), que são áreas protegidas, como nascentes, matas ciliares, topos de morro e áreas de alta declividade, cobertas ou não por vegetação nativa, com a função ambiental de preservar os recursos hídricos, a paisagem, a estabilidade geológica, a biodiversidade, o fluxo gênico de fauna e flora, proteger o solo e assegurar o bem-estar das populações humanas (BRASIL, 2012), visando apontar a presença ou ausência destas áreas e os impactos gerados ao substituí-las por outros tipos de uso da terra.

$\mathrm{O}$ aumento na robustez das técnicas de sensoriamento remoto, resultante do avanço dos sistemas sensores e das técnicas de processamento digital de imagens, possibilitou o alcance de um maior nível de detalhe para as análises sobre o uso da terra e a cobertura vegetal. Um dos avanços mais importantes observados nos últimos anos com relação às aplicações do mapeamento do uso da terra é o surgimento do paradigma da classificação orientada a objetos, referido comumente em inglês como GEOBIA, de Geospatial Object Based Image Analysis (BLASCHKE, 2010). De acordo com Marpu (2009), a GEOBIA mudou o paradigma da classificação e da análise das entidades presentes em imagens de satélite ao particioná-las em objetos significativos e avaliar suas características por meio de escalas espaciais, espectrais e temporais, de modo a gerar uma nova informação geográfica. Partindo do princípio de que os pixels são tecidos de uma estrutura que constitui uma imagem repleta de padrões espaciais, e, como tal, não deveriam ser prioritários em uma análise, a prioridade definida pela GEOBIA reúne os parâmetros estruturais de uma imagem, tais como cores, tons, texturas, padrões, formas, sombras e contexto, entre outros, o que aumenta o nível de detalhe e eleva o grau de análise acerca dos elementos da paisagem.

Diante do contexto apresentado, o objetivo deste trabalho consistiu em realizar uma análise multitemporal do uso da terra em Extrema (MG) para o período 2006-2016, a fim de verificar a efetividade dos programas de conservação do município. Tal período foi selecionado porque os anos abrangem o início da implementação do projeto municipal "Conservador das águas" e o período atual, possibilitando verificar o incremento nas 
áreas de APPs (nascentes, mata ciliar, topos de morro e áreas com declividade acima de $45^{\circ}$ ) derivado dos programas de preservação ambiental em execução no município. Para a realização do estudo, foi utilizada a técnica GEOBIA em razão das vantagens que esta técnica proporciona em relação aos classificadores tradicionais de base pixel a pixel.

\section{2. Área de Estudo}

O município de Extrema está localizado no sul do estado de Minas Gerais (Figura 1), encontrando-se na microrregião de Pouso Alegre, na divisa com o Estado de São Paulo, a $492 \mathrm{~km}$ distante da capital Belo Horizonte, e possui área municipal de aproximadamente $244 \mathrm{~km}^{2}$ com um total de 33.082 habitantes (IBGE, 2015).

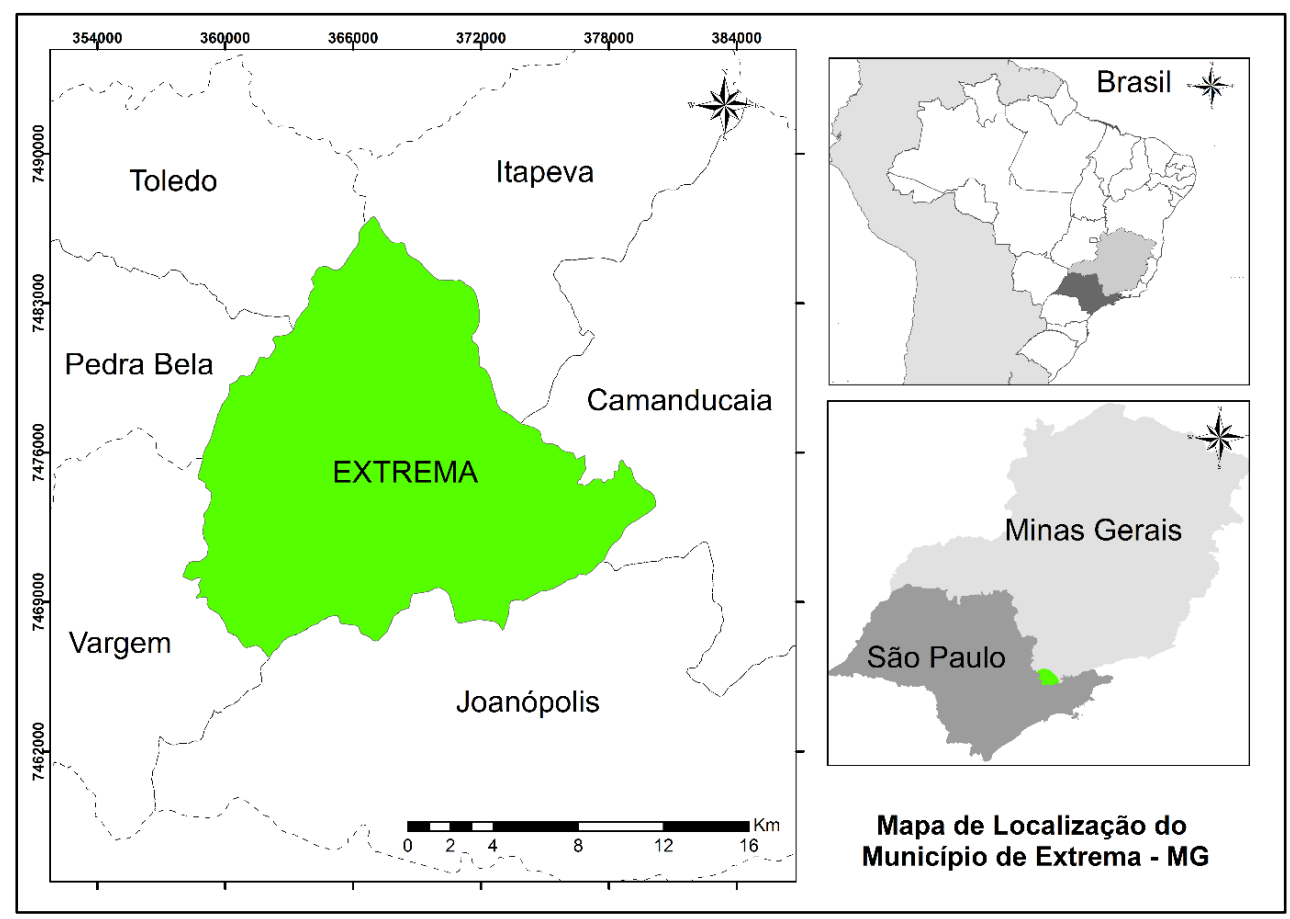

Figura 1: Localização da área de estudo, o município de Extrema, no estado de Minas Gerais.

O clima local, de acordo com a classificação de Köppen, é do tipo Cwb, ou seja, subtropical de altitude com inverno seco e verão ameno (ANA, 2008). Quanto à geologia, a Fundação Agência das Bacias PCJ (2013) identifica seis diferentes tipos de formações em Extrema: Charnoquitoide Foliado Ortognaisse, Suite Bragança Paulista, Granito Serra da Lapa, Granito Piracaia - Granitoide Alcalino, Paragnaisse Migmatizado e Ortognaisse Migmatítico. A pedologia de Extrema é formada por dois tipos principais de solo: Argissolo Vermelho-Amarelo distrófico (PVAd), que está presente em 54\% da área municipal, e Latossolo VermelhoAmarelo distrófico (LVAd), encontrado em 46\% do território (EXTREMA, 2013). Em relação à geomorfologia, o município está localizado na borda ocidental do maciço da Serra da Mantiqueira, tendo relevo acidentado com altitudes em torno de 970 metros (GONÇALVES, 2013).

Extrema está completamente inserida na bacia hidrográfica do rio Jaguari, que, juntamente com o seu reservatório, produz quase $70 \%$ da água do sistema Cantareira, responsável por abastecer a RMSP (GONÇALVES, 2013). No município, a água é utilizada, primordialmente, na indústria, irrigação, abastecimento público e para fins de saneamento ambiental. De acordo com o Plano Municipal de Recursos Hídricos, os principais usos da terra nas bacias hidrográficas correspondem à pastagem, reflorestamento e atividades agrícolas (EXTREMA, 2013).

\subsection{Programas de Conservação em Extrema}

O programa "Produtor de Água" tem como objetivo a proteção dos recursos hídricos do Brasil, focando na política de Pagamento por Serviços Ambientais (PSA), e apoia, orienta e certifica projetos que visam reduzir a erosão e o assoreamento de mananciais no meio rural. De adesão voluntária, o programa é voltado a produtores rurais que se propõe a adotar práticas e manejos conservacionistas para a proteção da água e do 
solo (ANA, 2017). O município de Extrema, que aderiu a este projeto em 2010 com o apoio de parcerias em nível municipal, estadual e federal, conta com 224 contratos assinados, somando 6.378 hectares (EXTREMA, 2013). As ações do programa são baseadas no aumento da cobertura vegetal nas bacias hidrográficas, na redução da poluição difusa rural, na aplicação do conceito de manejo integrado dos recursos e na garantia da sustentabilidade socioeconômica e ambiental, aplicadas através do PSA (ANA, 2017).

No entanto, vale ressaltar que Extrema já possuía um projeto em vigor anterior à adesão ao programa da ANA: o "Conservador das Águas", criado pela Lei ${ }^{\circ}$ 2.100/2005, com o intuito de implantar ações para a melhoria da qualidade e quantidade das águas no município como apontado em seu Art. $1^{\circ}$, pagando, assim, como acontece com o programa da ANA, por hectare com APP preservada (Lei n ${ }^{\circ}$ 2.100/2005, 2017).

\section{Materiais}

Para a realização do presente estudo, foram utilizadas imagens multitemporais obtidas pelos satélites Landsat-5 Thematic Mapper (TM) e Landsat-8 Operational Land Imager (OLI), além de dados do Modelo Digital de Elevação (MDE) Shuttle Radar Topography Mission (SRTM). As imagens Landsat, correspondentes à órbita/ponto 219/076, foram adquiridas em 14/09/2006 (TM) e 09/09/2016 (OLI). Conforme pode ser observado, ambas as cenas selecionadas foram adquiridas na mesma época do ano (agosto) com o objetivo de minimizar variações de brilho decorrentes de mudanças do ângulo solar, bem como mudanças fenológicas expressivas da cobertura vegetal e do calendário agrícola da região. As imagens foram obtidas do sítio do United States Geological Survey (USGS, 2017), que as disponibiliza já ortorretificadas, com um erro quadrático médio $\leq 12$ metros de raio, fato que as torna adequadas para a análise. Já os dados SRTM utilizados são de 1 arco por segundo, correspondente a 30 metros de resolução espacial, melhor resolução espacial dos dados do SRTM (NASA, 2014).

\section{Método}

\subsection{Classificações Orientadas ao Objeto}

A diferença básica entre os classificadores de base pixel a pixel e aqueles orientados a objetos é que o primeiro utiliza como referência para a classificação o valor individual de cada pixel, sem levar em consideração de maneira explícita a influência da vizinhança no processo de decisão. Na GEOBIA, no entanto, considera-se não apenas o valor do pixel em si, mas também dos vizinhos, delimitando áreas homogêneas tratadas como objetos. Para Jobin (2008) e Blaschke (2010), além da informação espectral pura, a GEOBIA caracteriza-se pelo incremento de informações relacionadas a objetos, como forma, textura e contexto, o que pode ser extremamente útil quando se tem o desafio de analisar paisagens heterogêneas. De acordo com Wicks et al. (2002), pelo fato da GEOBIA proporcionar uma representação mais realística e apropriada das feições e classes, ela também possui grande potencial de conferir maior grau de acurácia aos produtos finais de mapeamento.

Dentre as inúmeras vantagens que apresenta, a GEOBIA permite: particionar imagens em objetos, aproximando-se da maneira pela qual a visão humana organiza a paisagem para compreendê-la; reconhecer que pixels individuais não são objetos geográficos reais, complementando a relação intuitiva espacial entre os objetos da imagem e do mundo real; e aumentar as possibilidades de análise, uma vez que uma quantidade maior de variáveis, sejam espectrais (número de bandas consideradas), espaciais (área, direção, distância, largura), morfológicas (parâmetros de forma e textura), contextuais (relacionado com vizinhos, análises de proximidade) e temporais (séries temporais) podem ser incorporadas na classificação (NAVULUR, 2007; HAY; CASTILLA, 2008; NEUBERT et al., 2008). Nesse contexto, estudos recentes com o uso da GEOBIA demonstram que a qualidade de um mapeamento depende de fatores que transcendem os valores de refletância (CASTILLEJO-GONZALEZ et al., 2009; PEÑA-BARRAGÁN et al., 2011; SCHULTZ et al., 2016).

\subsection{Delimitações das Areas de Preservação Permanente}

Neste trabalho, foram consideradas as seguintes áreas de proteção seguindo os critérios do Código Florestal Brasileiro (BRASIL, 2012): mata ciliar, nascentes, topos de morro e áreas com declividade maior que $45^{\circ}$. Primeiramente, foi extraída a rede de drenagem do município de Extrema a partir do SRTM de forma automática com o uso do conjunto de ferramentas Hydrology, implementado no ArcGIS 10.3, sendo que foram considerados nessa etapa somente os rios de ordem maior ou igual a 3, segundo a classificação de Strahler (1952). Em seguida, foi gerado um buffer de 30 metros em torno das margens dos rios identificados na área de estudo, correspondente a área de proteção da mata ciliar. A delimitação das nascentes também foi realizada de 
forma automática utilizando a ferramenta Feature Vertice to Points, sendo que para este procedimento foram identificadas 878 nascentes. Posteriormente, foi gerado um buffer de 50 metros em torno de cada uma das nascentes identificadas seguindo os critérios da legislação vigente.

Já a declividade em Extrema foi determinada a partir da ferramenta Slope, que calcula a declividade em graus a partir da elevação disponibilizada pelo SRTM. Em seguida, foram separadas apenas as áreas com declividade maior ou igual a $45^{\circ}$, que segue a delimitação da área de APP estabelecida pelo Código Florestal Brasileiro. Por fim, com relação às áreas de proteção de topos de morro, a legislação estabelece que apenas os $2 / 3$ dos topos de morros com altura mínima de 100 metros e com inclinação média maior que 25 graus são destinados à proteção. Assim, para a identificação destas áreas, efetuou-se primeiramente o cálculo de amplitude do relevo e, em seguida, o terço superior de cada morro foi delimitado pelos valores dos pixels com amplitude maior que 0,667 .

\subsection{Mapeamento do Uso da Terra}

Visando atenuar efeitos atmosféricos e melhorar a precisão das informações espectrais de reflectância, foi realizada a correção atmosférica de ambas as imagens com o uso do modelo de transferência radiativa Second Simulation of the Satellite Signal in the Solar Spectrum Radiative Code (6S), utilizado para correção do espalhamento e da absorção da radiação na atmosfera (VERMOTE et al., 1997). O procedimento metodológico para a determinação do mapeamento do uso da terra envolveu a implementação da abordagem GEOBIA em ambiente eCognition Developer ${ }^{\circledR} 64$ (ED64) (TRIMBLE GEOSPATIAL, 2009) e pode ser dividido em quatro etapas principais: 1) geração de imagens índices com o objetivo de realçar classes de interesses presentes; 2) geração de geo-objetos por meio do segmentador Multiresolution Segmentation (MS); 3) classificação dos geo-objetos por meio do algoritmo Support Vector Machine (SVM); e 4) correção dos erros observados em uma etapa de pós-classificação.

Além dos atributos espectrais, espaciais, morfológicos, contextuais e temporais, três índices espectrais foram gerados com o objetivo de ampliar a separabilidade espectral das classes mapeadas (mata, agropecuária, corpo hídrico, silvicultura e uso urbano) e melhorar o resultado da segmentação: Normalized Difference Vegetation Index (NDVI) (ROUSE et al. 1973), Soil-adjusted Vegetation Index (SAVI) (HUETE, 1988) e Normalized Difference Water Index (NDWI) (GAO, 1996). Estes índices foram utilizados por serem sensíveis à variação de vegetação verde, solo exposto e corpos d'água.

Para a segmentação das imagens foi utilizado o algoritmo MS, o qual, segundo Espindola e Câmara (2007), agrupa os pixels de cada objeto em função da definição de seis parâmetros: fator de escala, forma, suavidade, compacidade, cor e peso, atribuídos a cada banda. Os parâmetros de segmentação foram definidos com base na realização de testes: foram testadas diferentes segmentações, e escolhida a que apresentou maior semelhança entre os polígonos gerados e os alvos encontrados na imagem. Após a segmentação, visando agrupar objetos vizinhos com características semelhantes, formando objetos maiores com características espectrais semelhantes, procedeu-se a aplicação do algoritmo Spectral Difference Segmentation (SDS), que agrupa objetos vizinhos quando a sua diferença espectral for menor que a máxima diferença espectral estabelecida no parâmetro.

Ao final, para realizar a classificação dos geo-objetos, foi utilizado o classificador SVM, que seleciona um pequeno número de ocorrências de fronteiras críticas entre as tipologias da paisagem, as quais são denominadas "Vetores de suporte" de cada classe, que são empregadas para construir uma função linear discriminante que as separam de forma mais ampla possível (WITTEN et al., 2011).

\section{Resultados e Discussão}

O mapeamento do uso da terra e cobertura vegetal (Figura 2) permitiu identificar e analisar a dinâmica temporal das ações antrópicas sobre o município de Extrema por meio da definição de 5 classes de uso: mata, agropecuária, corpos d'água, silvicultura e uso urbano.

No ano de 2006 havia uma predominância do uso voltado para a atividade agropecuária (Cultivos agrícolas e Pastagens), que somados contabilizavam $151 \mathrm{~km}^{2}$. À época, a soma de toda a área coberta por mata no município representava $86 \mathrm{~km}^{2}$. É importante ressaltar que muito desta vegetação era formada por pequenos fragmentos, apresentando apenas algumas áreas mais expressivas, como, por exemplo, no extremo sul, centro leste e noroeste do município. Nota-se também que a silvicultura era pouco difundida, com apenas $0,5 \mathrm{~km}^{2} \mathrm{de}$ área plantada nas regiões sul e centro-oeste. Os corpos hídricos representavam apenas $2 \mathrm{~km}^{2} \mathrm{em} \mathrm{2006.} \mathrm{Ainda,}$ 
como a economia de Extrema é baseada nas atividades agrícolas, seu uso urbano correspondia somente a 5 $\mathrm{km}^{2}$ de área.

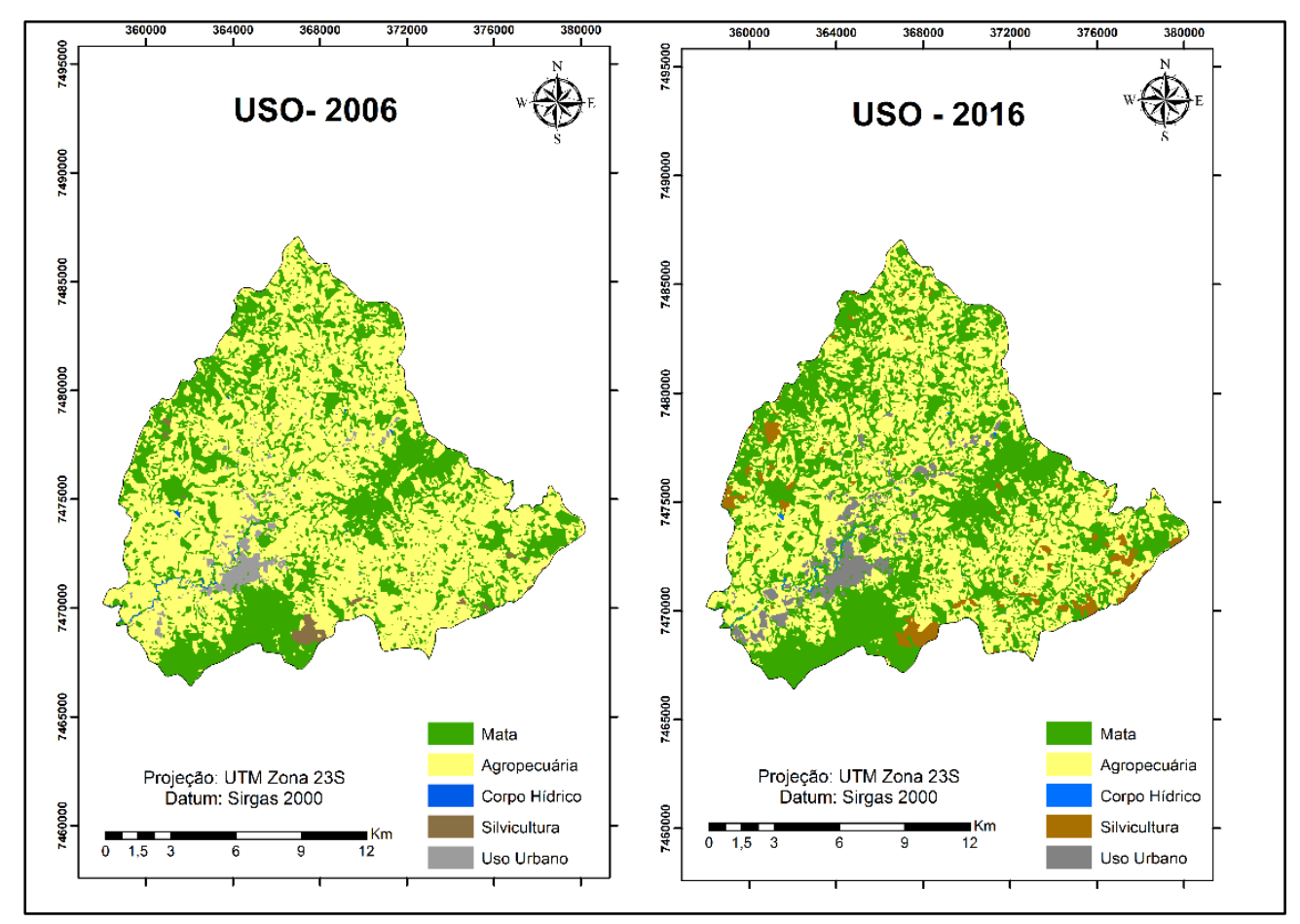

Figura 2: Mapas de uso da terra do município de Extrema para os anos de 2006 e 2016.

O mapa de uso da terra e cobertura vegetal de 2016 apresentou aumento da área da classe Mata no município. Esta classe, que em 2006 ocupava $86 \mathrm{~km}^{2}$, passou a ocupar $108 \mathrm{~km}^{2}$. Tal aumento sugere que, como demonstrado por Silva (2013), há aumento significativo dos serviços ambientais prestados, o que implica na diminuição de eventos de inundação e aumento da vazão na estiagem, além da melhoria na qualidade dos recursos hídricos devido à maior proteção. Como consequência deste aumento da vegetação natural, houve redução de $31 \mathrm{~km}^{2}$ das áreas voltadas à agropecuária. Cabe ressaltar que o reflorestamento da região não foi somente feito com vegetação natural; houve um aumento de quase $9 \mathrm{~km}^{2}$ da área da classe Silvicultura. Possivelmente, a diminuição dos corpos hídricos (de $2 \mathrm{~km}^{2}$ para $\left.0,5 \mathrm{~km}^{2}\right)$ ocorreu por dois fatores: em $2016 \mathrm{o}$ aumento das áreas de mata ciliar dificultou a classificação dos corpos hídricos; ainda, o período recente se encaixa dentro do processo de recuperação do ano de grave seca no sudeste do Brasil em 2014 (COELHO et al., 2016), o que pode ter diminuído o volume dos corpos hídricos e tem reflexo ainda em 2016. Por fim, foi identificado aumento da área urbana, como consequência do processo de incremento que as pequenas e médias cidades vêm apresentando nas últimas décadas (FONSECA, 2009). A Tabela 1 demonstra as mudanças observadas no período analisado.

Tabela 1: Áreas recobertas por cada tipo de uso da terra e sua variação.

\begin{tabular}{cccccc}
\hline & $\begin{array}{c}\text { Área 2006 } \\
\left(\mathbf{k m}^{\mathbf{2}}\right)\end{array}$ & $\begin{array}{c}\text { Porcentagem } \\
\mathbf{2 0 0 6}(\mathbf{\%})\end{array}$ & $\begin{array}{c}\text { Área 2016 } \\
\left.\mathbf{( k m}^{\mathbf{2}}\right)\end{array}$ & $\begin{array}{c}\text { Porcentagem } \\
\mathbf{2 0 1 6}(\mathbf{\%})\end{array}$ & $\begin{array}{c}\text { Variação } \\
\mathbf{( \% )}\end{array}$ \\
\hline Mata & 86 & 35 & 108 & 44 & $+9,0$ \\
\hline Agropecuária & 151 & 62 & 120 & 49 & $-13,0$ \\
\hline Corpo Hídrico & 2 & 0,7 & 0,5 & 0,3 & $-0,4$ \\
\hline Silvicultura & 0,5 & 0,3 & 9 & 3,7 & $+3,4$ \\
\hline Uso Urbano & 5 & 2 & 7 & 3 & $+1,0$ \\
\hline
\end{tabular}

A Figura 3 ilustra as áreas de APPs em Extrema e o uso da terra para os anos 2006 e 2016. Foi possível identificar que $31 \%$ da área do município $\left(76,5 \mathrm{~km}^{2}\right)$ corresponde a áreas de APP, de acordo com a legislação vigente. No ano de 2006, as áreas de APP eram em sua maior parte ocupadas por usos agrícolas (52\% do total). Apesar da obrigatoriedade legal em se preservar 100\% destas áreas, apenas $45 \%$ delas estavam recobertas por matas. Os demais tipos de uso são poucos expressivos em termos de área ocupada, pois somados correspondem a 2,5\% da área total de APP no município. Já em 2016, é possível notar os efeitos positivos dos programas de 
preservação implementados no município, pois houve uma alteração no uso da terra: as matas se tornaram a classe de maior expressão nas áreas de APP, representando 55\% destas. O incremento destas áreas demonstra que as funções ambientais de preservação dos recursos hídricos, da paisagem, da biodiversidade, da estabilidade geológica, de proteção do solo e do bem-estar das populações estão sendo melhor executadas (MMA, 2011), e vai de encontro com o proposto por Attanasio et al. (2012), que afirmam que a preservação das APPs está intimamente ligada com a qualidade e a produção de água nas bacias hidrográficas.

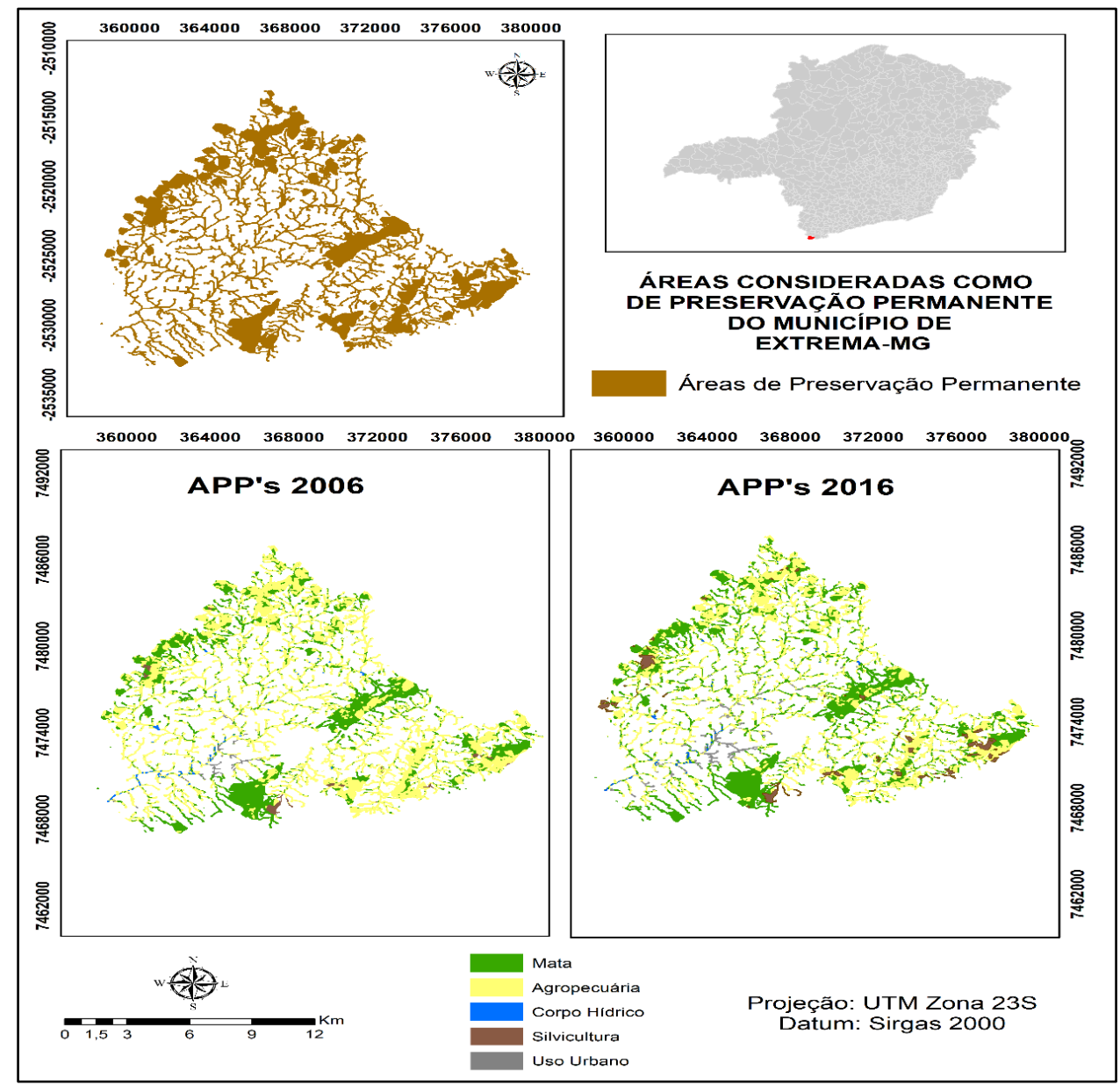

Figura 3: Localização espacial e o uso da terra nas áreas de APP de Extrema em 2006 e 2016.

O aumento significativo das áreas de mata fez com que as áreas destinadas à agropecuária reduzissem para $38,5 \%$ do total. No entanto, esta porcentagem ainda é considerada elevada para áreas que necessitam de proteção integral. Notou-se também que a silvicultura teve um significativo aumento, passando de $0,45 \%$ para $4,25 \%$ do total, o que pode ser explicado pela falta de interesse econômico que esta atividade proporcionava em 2006, e, com a valorização do produto, os cultivos expandiram em 2016. Ainda, nota-se que mesmo após os programas de incentivo à preservação ambiental houve um ligeiro aumento no uso urbano em áreas de APP, com um acréscimo de aproximadamente 1\% em relação a 2006, conforme demostra a Tabela 2.

Tabela 2: Comparação interanual dos tipos de uso.

\begin{tabular}{cccccc}
\hline & Área 2006 $\left(\mathbf{k m}^{\mathbf{2}}\right)$ & $\begin{array}{c}\text { Porcentagem } \\
\mathbf{2 0 0 6}(\mathbf{\%})\end{array}$ & Área 2016 $\left.\mathbf{( k m}^{\mathbf{2}}\right)$ & $\begin{array}{c}\text { Porcentagem } \\
\mathbf{2 0 1 6}(\mathbf{\%})\end{array}$ & $\begin{array}{c}\text { Variação } \\
\mathbf{( \% )}\end{array}$ \\
\hline Mata & 31,5 & 45 & 39 & 55 & $+10,0$ \\
\hline Agropecuária & 37 & 52,5 & 27 & 38,5 & $-14,0$ \\
\hline Corpo Hídrico & 0,9 & 1,25 & 0,3 & 0,5 & $-0,75$ \\
\hline Silvicultura & 0,25 & 0,35 & 3 & 4,25 & $+3,9$ \\
\hline Uso Urbano & 0,75 & 0,9 & 1,1 & 1,75 & $+0,8$ \\
\hline
\end{tabular}


A mudança de uso da terra em cada um dos quatro tipos de APP abordados é demostrada na Figura 4. As áreas de declividade $>45^{\circ}$ apresentam o maior percentual de cobertura por mata, chegando a quase $80 \%$ em 2016. Já a Mata Ciliar teve um incremento de mais de 20\%, e uma consequente diminuição da Agropecuária (18\%). Ainda, o aumento da Mata foi expressivo nas nascentes (cerca de 16\%), enquanto que os topos de morro apresentaram o menor incremento, porém ainda significativo $(10 \%)$. Este fato é corroborado por Pacheco et al. (2017), que afirmam que a política pública do projeto Conservador das Águas foi eficiente na aplicação do reflorestamento no município, cobrindo 6.135 hectares, onde a recomposição das matas ocorreu majoritariamente em áreas de preservação permanente. Seguindo a mesma linha, Jardim e Bursztyn (2015) indicam que a aplicação do pagamento por serviços ambientais em Extrema facilita o aumento da preservação das áreas de preservação permanente, à medida que a compensação financeira promovida diretamente aos produtores rurais incentiva o cumprimento das metas estabelecidas.
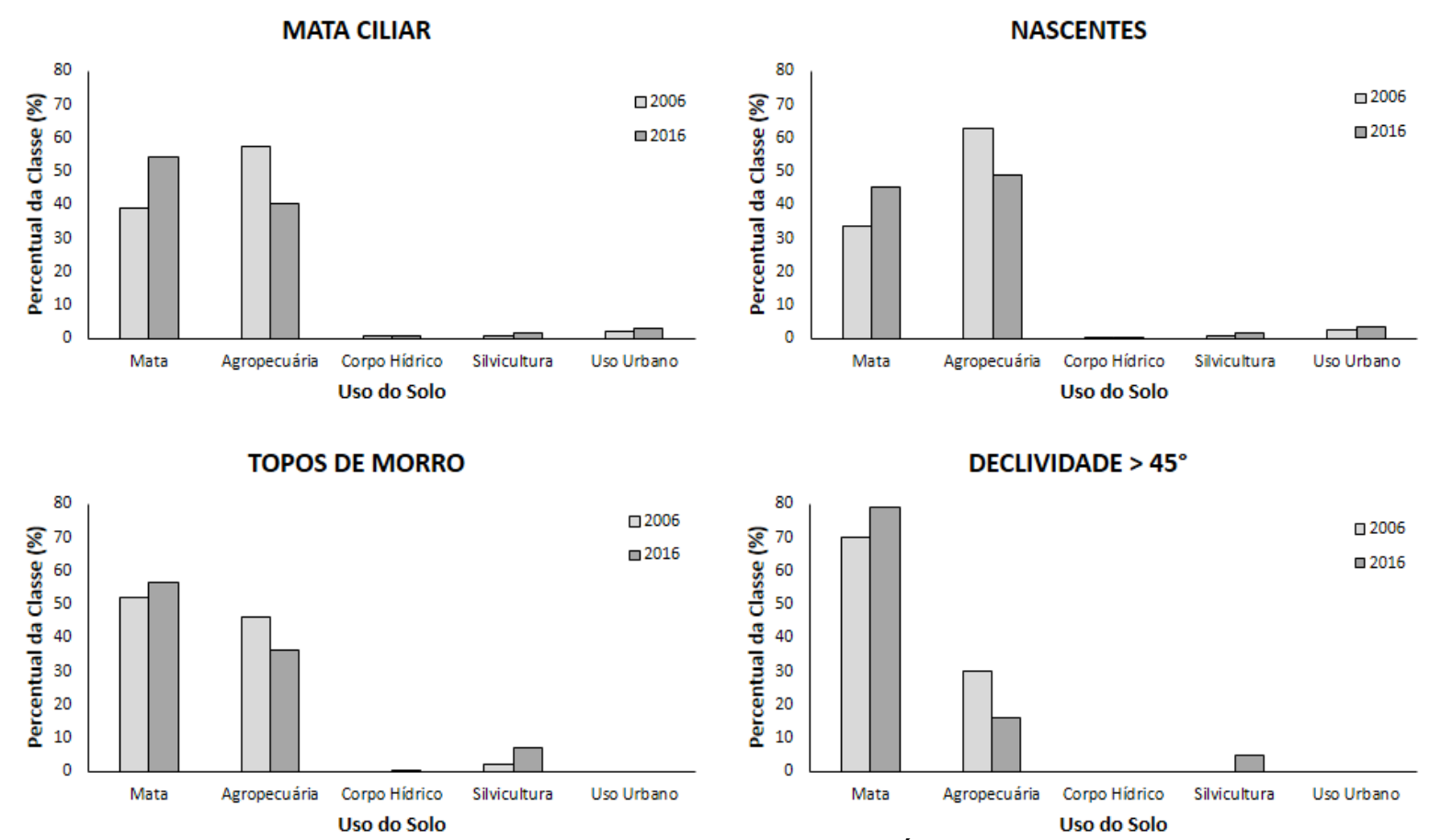

Figura 4: Alterações do uso da terra nos distintos tipos de Áreas de Preservação Permanente.

Por fim, é importante mencionar que o principal aspecto que agregou dificuldades na classificação e, por conseguinte, geraram erros que foram corrigidos na etapa de pós-classificação refere-se à influência do relevo no comportamento espectral dos objetos. Por se tratar de uma área com relevo bastante dissecado, as variações de iluminação causadas pela disposição do relevo dificultaram a realização do mapeamento principalmente nas áreas mais declivosas em razão tanto do efeito de sombreamento quanto da iluminação excessiva. Mesmo utilizando imagens índices geradas por razões de bandas que atenuam as variações causadas pelo efeito topográfico, os problemas persistiram. Nas faces sombreadas, áreas de mata foram confundidas com os corpos hídricos, e nas faces de maior iluminação, imprecisões foram observadas envolvendo silvicultura e mata.

\section{Conclusões}

A aplicação da técnica da classificação orientada ao objeto a partir de dados orbitais se mostrou eficiente na análise da dinâmica do uso da terra em Extrema, tendo em vista que foi possível determinar o padrão de uso e ocupação na área de estudo para as datas analisadas. Ainda, a análise multitemporal é uma ferramenta importante para o diagnóstico, planejamento e gestão dos recursos ambientais nos municípios brasileiros, principalmente no sentido de verificar o padrão de evolução das ações humanas sobre o espaço ao longo do tempo. Para o município de Extrema, verificou-se um aumento de cerca de $10 \%$ da área de mata além de uma redução significativa das áreas destinadas a agropecuária entre 2006 e 2016, tanto para o município em geral quanto para apenas as áreas de preservação permanente, sendo ainda que as áreas de mata aumentaram em todos os tipos de APP analisados. Estas alterações na dinâmica de uso da terra podem ser explicadas pela aplicação dos programas de conservação empregados no município, que a partir da definição de metas ambientais para os produtores rurais, incentivados pelo pagamento por serviços ambientais, favorece o aumento da vegetação nativa. Ainda, sugere-se que o monitoramento do uso da terra continue ao longo dos 
próximos anos para que seja comprovada a importância da aplicação do programa na conservação dos serviços ecossistêmicos locais, além de ratificar o caso de Extrema como um exemplo a ser seguido pelos demais municípios brasileiros. Por fim, sugere-se trabalhos futuros no sentido de avaliar o aumento da disponibilidade hídrica gerado pela adesão aos programas, especialmente pelo fato de que a área de estudo comporta cabeceiras de drenagem que abastecem duas metrópoles do estado de São Paulo: as cidades de Campinas e São Paulo.

\section{Agradecimentos}

À Fundação de Amparo à Pesquisa do Estado de São Paulo (FAPESP, processo 2016/19020-0), à Coordenação de Aperfeiçoamento de Pessoal de Nível Superior (CAPES, processo 1435897) e ao Conselho Nacional de Pesquisa (CNPq, processo 62898/2015-0) pela concessão de bolsas de doutorado que permitiram o desenvolvimento deste estudo.

\section{REFERÊNCIAS}

AGÊNCIA NACIONAL DE ÁGUAS (ANA). Programa Produtor de Água. ANA: Brasília. 2008. Disponível em: <www.ana.gov.br>. Acesso em: 23 fev. 2017.

AGÊNCIA NACIONAL DE ÁGUAS (ANA). Programa Produtor de Água. 2017. Disponível em: $<$ http://produtordeagua.ana.gov.br/>. Acesso em: 10 mar. 2017.

ATTANASIO, C. M.; GANDOLFI, S.; ZAKIA, M. J. B.; VENIZIANI JUNIOR, J. C.; LIMA, W. P. A importância das áreas ripárias para a sustentabilidade hidrológica do uso da terra em microbacias hidrográficas. Bragantia, v.71, n.4, p.493-501, 2012.

BLASCHKE, T. Object based image analysis for remote sensing. ISPRS Journal of Photogrammetry and Remote Sensing, v.65, n.1, p.2-16, 2010. Disponível em: <http://dx.doi.org/ 10.1016/j.isprsjprs.2009.06.004>.

BRASIL. Lei 12.651, de 25 de maio de 2012 - Código Florestal. Áreas de Preservação Permanente. Disponível em: <http://www2.camara.leg.br/legin/fed/lei/2012/lei-12651-25-maio-2012-613076-norma-pl.html>. Acesso em: 03 mai. 2017.

CASTILLEJO-GONZALEZ, I. L.; LÓPEZ-GRANADOS, F.; GARCIA-FERRER, A.; PEÑA-BARRAGAN, J. M.; JURADO-EXPÓSITO, M.; SANCHEZ-DE LA ORDEN, M.; GONZALEZ-AUDICANA, M. Object and pixel-based analysis for mapping crops and their agroenvironmental associated measures using QuickBird imagery. Computers and Electronics in Agriculture, v.68, pp.207-215, 2009

COElHO, C. A. S.; DE OLIVEIRA, C. P.; AMBRIZZI, T.; REBOITA, M. S.; CARPENEDO, C. B.; CAMPOS, J. L. P. S.; TOMAZIELLO, A. C. N.; PAMPUCH, L. A.; CUSTÓDIO, M. D. S.; DUTRA, L. M. M.; DA ROCHA, R. P; REHBEIN, A. The 2014 southeast Brazil austral summer drought: regional scale mechanisms and teleconnections, Climate Dynamics, v.46, n.11, 2016. Disponível em: $<$ https://doi.org/10.1007/s00382-015-2800-1>.

EXTREMA, Prefeitura Municipal de. Dados da Cidade. 2013. Disponível em: $<$ http://extrema.mg.gov.br/dados-da-cidade-2/>. Acesso em: 25 nov. 2016.

EXTREMA. Projeto Conservador das Águas, Extrema/MG. 2017. Disponível em: $<$ http://extrema.mg.gov.br/site/wp-content/uploads/2011/10/PROJETO-CONSERVADOR-DASAGUAS.pdf $>$. Acesso em: 10 mar. 2017.

FLORENZANO, T. G. Geotecnologias na Geografia Aplicada: Difusão e Acesso. Revista do Departamento de Geografia, n. 17, p. 24-29, 2005.

FONSECA, C. E. O crescimento e a expansão urbana e industrial no município de Extrema, Minas Gerais, a partir da duplicação da rodovia Fernão Dias, BR 381. 131p. Dissertação de Mestrado. Pontífica Universidade Católica de São Paulo. São Paulo. 2009.

GAO, B. NDWI A Normalized Difference Water Index for Remote Sensing of Vegetation Liquid Water From Space. Remote Sensing of Environment, n. 58, p.257-266, 1996.

GONÇALVES, H. Pagamentos por serviços ambientais segunda a ótica da comunidade envolvida - O caso do projeto "Conservador das Águas", Extrema, MG. 208p. Dissertação de Mestrado. Universidade de São Paulo. Piracicaba. 2013. HAY, G. J.; CASTILLA, G. Geographic Object-Based Image Analysis (GEOBIA): A new name for a new discipline? In: Object-Based Image Analysis - Spatial Concepts for 
Knowledge-driven Remote Sensing Applications, T. Blaschke, T., Lang, S., Hay, G. J., (editores), SpringerVerlag, 1.4, pp. 81- 92, 2008.

HUETE, A. A soil-adjusted vegetation index (SAVI). Remote Sensing of Environment, n. 25, 295-309, 1988.

INSTITUTO BRASILEIRO DE GEOGRAFIA E ESTATÍSTICA (IBGE). Censo 2010. Disponível em: $<$ http://censo2010.ibge.gov.br/>. Acesso em: 20 fev. 2017.

INSTITUTO BRASILEIRO DE GEOGRAFIA E ESTATÍSTICA (IBGE). Estimativas Populacionais. 2015. Disponível em: <ibge.gov.br/home/estatistica/populacao/estimativa2015/>. Acesso em: 20 fev. 2017.

FUNDAÇÃO AGÊNCIA DAS BACIAS PCJ. Plano Municipal de Recursos Hídricos Extrema/MG. 2013.

JARDIM, M. H.; BURSZTYN, M. A. Pagamento por serviços ambientais na gestão de recursos hídricos: o caso de Extrema (MG). Engenharia sanitária e ambiental, v.20, n.3, p.353-360, 2015.

JACOBI, P. R. Meio ambiente e sustentabilidade. In: Meio Ambiente e Sustentabilidade. O município no século XXI. São Paulo: CEPAM, p.175-183, 1999.

JOBIN, B.; LABRECQUE, S.; GRENIER, M.; FALARDEAU, G. Object-based classification as an alternative approach to the traditional pixel-based classification to identify potential habitat of the Grasshopper Sparrow. Environmental Management, n. 41, pp. 20-31, 2008.

Lei $\mathrm{n}^{\circ}$ 2.100/2005 - Projeto Conservador das Águas. Disponível em: $<$ http://www.extrema.mg.gov.br/conservadordasaguas/lei-n-2100.pdf>. Acesso em: 13 mar. 2017.

Lei $\mathrm{n}^{\circ}$ 2100/2005. Projeto Conservador das Águas. Extrema-MG. Disponível em: $<$ http://www.extrema.mg.gov.br/conservadordasaguas> Acesso em: 03 mai. 2016.

MARPU, P. R. Geographic Object-based Image Analysis. Freiberg, 2009. 121f. Tese de Doutorado. Faculty of Geosciences, Geo-Engineering and Mining Technische Universität Bergakademie Freiberg, 2009.

MINISTÉRIO DO MEIO AMBIENTE (MMA). Áreas de Preservação Permanente e Unidades de Conservação x Áreas de Risco: O que uma coisa tem a ver com a outra? 2011.

MORAES, E. C. Fundamentos de Sensoriamento Remoto. INPE, São José dos Campos, 2002.

NASCIMENTO, M. C. DO; SOARES, V. P.; RIBEIRO, C. A. A. S.; SILVA, E. Uso do geoprocessamento na identificação de conflito de uso da terra em áreas de preservação permanente na bacia hidrográfica do Rio Alegre, Espírito Santo. Ciência Florestal, v.15, p.207-220, 2005.

NAVULUR, K. Multispectral image analysis using the object-oriented paradigm. Boca Raton: CRC, 184p, 2007.

NEUBERT, M.; HEROLD, H.; MEINEL, G. Assessing image segmentation quality: concepts, methods and application. In: BLASCHKE, T.; LANG, S.; HAY, G.J. (Ed.). Object-based image analysis spatial concepts for knowledge-driven remote sensing applications. New York: Springer-Verlag, pp. 769-784, 2008.

NORTH AMERICAN SPACE AGENCY (NASA). 2014. Shuttle Radar Topography Mission: The Mission to Map the World. Disponível em: <http://www2.jpl.nasa.gov/srtm>. Acesso em: 20 out. 2016.

PACHECO, B. D. O. S.; ALBUQUERQUE, C. C. A. C.; TORRES FILHO, D. M.; SANTOS, E. K. M. O Projeto Conservador das Águas: análise de uma política pública em Extrema/MG. Revista Brasileira de Desenvolvimento Regional, v.5, n.1, 159-182, 2017.

PEÑA-BARRAGAN, J. M.; NGUGI, M. K.; PLANT, R. E.; SIX, J. Object-based crop identification using multiple vegetation indices, textural features and crop phenology. Remote Sensing of Environment, v.115, pp.1301-1316, 2011.

PESSOA, M. C.P. Y.; FERNANDES, E. N. Modelagem matemática e simulação de sistemas aplicadas ao planejamento ambiental e da atividade agrícola. In: Planejamento ambiental do espaço rural com ênfase para microbacias hidrográficas: manejo de recursos hídricos, ferramentas computacionais e educação ambiental. Março Antonio Ferreira Gomes, Maria Conceição Peres Young Pessoa, editores técnicos. Brasília, DF. Embrapa, 2010, 407 p.

ROUSE, J. W.; HAAS, R. H.; SCHELL, J. A.; DEERING, D. W. Monitoring vegetation systems in the Great Plains with ERTS. In 3rd ERTS Symposium, 1973. Anais... NASA, 1973, p. 309-317. 
SCHULTZ, B.; FORMAGGIO, A. R.; EBERHARDT, I. D. R.; SANCHES, I. D. A.; OLIVEIRA, J. C.; LUIZ, A. J. B. Classificação orientada a objetos e, imagens multitemporais Landsat aplicada na identificação de cana-de-açúcar e soja. Revista Brasileira de Cartografia, v.68, n.1, pp.131-143, 2016.

SABESP. Sistema $2017 . \quad$ Cantareira. Disponível em: $<$ http://site.sabesp.com.br/site/interna/Default.aspx?secaoId=132>. Acesso em: 25 out. 2017.

SEMACE. Superintendência Estadual do Meio Ambiente - CEARÁ. Instrumentos Administrativos e Judiciais de Defesa Ambiental sob a Ótica Municipalista. Fortaleza, 1994.

SILVA, J. M. O serviço ambiental hidrológico das áreas de proteção permanente: um estudo de caso com modelagem numérica em pequena e mesoescala na bacia do Rio Piracicaba. 100p. Tese de Doutorado. Universidade de São Paulo. São Paulo. Novembro de 2013.

STRAHLER, A. N. Hypsometric (area-altitude) - analysis of erosion al topography. Geological Society of America Bulletin, v.63, n.10, p.1117-1142, 1952.

TRIMBLE GEOSPATIAL. Definiens eCognition developer. Version 8. Munich: Trimble GeoSpatial, 2009.

UNITED STATES GEOLOGICAL SURVEY (USGS). 2017.

VERMOTE, E. F.; TANRÉ, D.; DEUZI, J. L.; HERMAN, M.; MORCRETTE, J. J. Second simulation of the satellite signal in the solar spectrum: an overview. IEEE Transactions on Geoscience and Remote Sensing, v.35, n.3, p.675-686, 1997.

WICKS, T.; SMITH, G.; CURRAN, P. Polygon-based aggregation of remotely sensed data for regional ecological analysis. International Journal of Applied Earth Observation and Geoinformation, v.4, n.2, pp.161-173, 2002.

WITTEN, I. H.; FRANK, E.; MARK, A. H. Data Mining: Practical Machine Learning Tools and Techniques. Third. p. 629, 2011. 